ing the smallest amount of dissolved salts. It agrees fairly well with the calculated composition of the $5: 6: 2$ salt, which forms also from alcohol. The salt can be recrystallized. Mercuric chloride and potassium chloride were therefore dissolved in hot acetone in the proportion in which they are present in the $5: 6: 2$ salt and the solution was allowed to crystallize at $25^{\circ}$. The analytical results were:

\begin{tabular}{|c|c|c|}
\hline & Found. & $\begin{array}{l}\text { Calculated for } \\
{ }_{5} \mathrm{KCl} .6 \mathrm{HgCl}_{2}, 2 \mathrm{C}_{3} \mathrm{H}_{6} \mathrm{O}\end{array}$ \\
\hline $\mathrm{HgCl}_{2}$. & $77 \cdot 52$ & 76.87 \\
\hline $\mathrm{KCl} \ldots$ & 17.46 & 17.64 \\
\hline $\mathrm{C}_{3} \mathrm{H}_{6} \mathrm{O} \ldots \ldots \ldots \ldots \ldots$ & 5.02 (Diff.) & $5 \cdot 47$ \\
\hline
\end{tabular}

Acetone is lost rapidly by both salts in the air, so this constituent varies considerably from the calculated values in most of the analyses.

The salts with potassium chloride obtained from the three solvents are summarized in the following table:

\begin{tabular}{|c|c|c|}
\hline From water. & $\begin{array}{c}\text { From alcohol. } \\
\qquad \ldots \ldots\end{array}$ & $\begin{array}{l}\text { From acetone. } \\
\mathrm{KCl} .5 \mathrm{HgCl}_{2} \cdot \mathrm{C}_{3} \mathrm{H}_{6} \mathrm{O}\end{array}$ \\
\hline $\begin{array}{c}\mathrm{KCl} .2 \mathrm{HgCl}_{2}, 2 \mathrm{H}_{2} \mathrm{O} \\
\ldots \ldots \ldots\end{array}$ & ${ }_{5} \mathrm{KCl} .6 \ddot{\mathrm{HgCl}}_{2 .} \ddot{\mathrm{C}}_{2} \mathrm{H}_{6} \mathrm{O}$ & ${ }_{5} \mathrm{KCl} .6 \mathrm{HgCl}_{2} \cdot 2 \mathrm{C}_{3} \mathrm{H}_{6} \mathrm{O}$ \\
\hline $\begin{array}{l}\mathrm{KCl} \cdot \mathrm{HgCl}_{2} \cdot \mathrm{H}_{2} \mathrm{O} \\
2 \mathrm{KCl} \cdot \mathrm{HgCl}_{2} \cdot \mathrm{H}_{2} \mathrm{O}\end{array}$ & $\begin{array}{l}\ldots \ldots \\
\ldots \ldots\end{array}$ & $\begin{array}{l}\ldots \ldots \cdots \\
\ldots \ldots \ldots\end{array}$ \\
\hline
\end{tabular}

It will be noticed that none of the types of salts formed from water are formed from the other solvents, and further, that the $I$ : $5:$ I salt from acetone is not formed either from water or from alcohol. The I : 5 salt without water has, however, been prepared with rubidium and with caesium.

From the results obtained in this investigation the conclusion may be drawn that when a double salt is formed containing the solvent, the latter is an essential constituent of the salt and is as important in determining the type of double salt formed, as are the individual salts. The substitution of one solvent for another may even prevent a double salt from forming.

SHEtFieid Chemical LAgoratory, New Haven, Conn.

\title{
ADDITIONAL NOTES ON THE ALKALI AND ALKALI EARTH AMALGAMS.
}

By G. MCP. SMith and H. C. Bennett. Received March 8, 1910.

The problem as to the nature of the solid amalgams was first systematically investigated by Kerp, ${ }^{1}$ who carried out exact solubility determinations with certain members of the class. In every case the solid as well as the saturated solution in equilibrium with it was analyzed.

$1 Z$. anorg. Chem., I7, 284 (1898). 
In a second paper, ${ }^{1}$ by Kerp and Böttger, the solubility determinations were continued, and the results were interpreted according to the phase rule. The various phenomena which are possible are discussed at length by Kerp and Böttger. By determining for various temperatures the composition of each of the phases in equilibrium, Kerp and Böttger were in a position to judge whether the solid phase, owing to its constant composition at different temperatures, was to be classed as a chemical individual, and, if so, between what temperatures it was capable of existence.

An undoubted disadvantage of Kerp and Böttger's method lies in the fact that it is extremely difficult to completely separate the crystalline amalgams from the adhering mother liquor, which renders the analytical results for the solid phases very uncertain. ${ }^{2}$ For example, the work of Maey, ${ }^{3}$ which is free from this error, has rendered the existence of the compound $\mathrm{NaHg}_{\theta}$, described by Kerp and Böttger, very uncertain.

In our work on the electrolytic preparation of the alkali and alkali earth amalgams, ${ }^{4}$ in which large quantities of the solid amalgams were at our disposal, the crystals left behind on filtration showed in several instances a higher alkali content than was obtained by Kerp and Böttger. We therefore repeated their work, at the ordinary temperature, with the addition that the mother liquor left behind on filtration was removed as far as was possible, without undue risk of oxidation, by means of a high-speed electric centrifugal machine. We have included caesium amalgam, which Kerp and Böttger did not prepare, and have also in certain cases repeated their solubility determinations.

Unless otherwise stated, the solid amalgams, obtained by filtration through chamois skin on the filter pump, were introduced into narrow glass tubes (internal diameter $=8 \mathrm{~mm}$.), in which they were melted; while in this condition, the ends of the tubes were vigorously tapped upon the desk, in order to jar to the surface the air bubbles and any hydroxide which might be present. The tubes were then sealed off just above the surface of the melt. They were later cut into 3 -centimeter sections, and the amalgams were removed in the form of compact, crystalline sticks, which were centrifuged at high speed for 5-10 minutes in open Gooch crucibles, without filters. Samples weighing I-8 grams, from which the outer, slightly tarnished surfaces had been removed with a knife, were then at once analyzed. The samples were covered with water (to which a few drops of methyl orange were added), o. r $N$ hydrochloric acid was run in just to neutral reaction, an excess was then

${ }^{1} Z$. anorg. Chem., 25, I (1900).

${ }^{2}$ Cf. Kerp and Böttger, Loc. cit., p. 8; also Abegg's "Handbuch," Vol II, part 2, p. 573 .

3. physik. Chem., 29, II9 (1899).

- Thus Journal, 3r, 799 (I909). 
added, and, after the decomposition of the amalgam, this was titrated back with o. I $N$ sodium hydroxide. The water had acquired its alkalinity, which was generally equivalent to about I cc. of o. I $N$ acid, from the oxidation products present; its action on the amalgam itself was negligible. The alkali content of an amalgam was therefore calculated from the volume of acid that was required to actually decompose the amalgam.

Caesium amalgam, in the form of crystalline sticks, was rapidly oxidized in the centrifuge. Large crystals, obtained by allowing the liquid amalgam, saturated at the ordinary temperature, to stand for several hours in cracked ice, were, however, centrifuged at high speed for $5 \mathrm{~min}$ utes without apparent oxidation. Two samples, weighing 7-8 grams, gave, on analysis, 5.05 and 5.07 per cent. of caesium. This was the highest caesium content we obtained. In the cases of sodium and lithium amalgams the crystalline sticks remained compact throughout the treatment, and the results are considered reliable. On disintegrating the solid sticks of the centrifuged sodium amalgam, fine, needle-like crystals of a splendent metallic luster were obtained. To the eye they showed no sign of oxidation, and, unlike those of caesium, rubidium and potassium amalgams, they were clean-cut and free from any indication of mother-liquor. The results for the crystalline amalgams are given as a whole in Table I:

TABLE I.

\begin{tabular}{|c|c|c|c|c|c|}
\hline \multirow[b]{2}{*}{ Amalgam. } & $\begin{array}{l}\text { Alkali con } \\
\text { of crystals separated }\end{array}$ & $\begin{array}{l}\text { ontent } \\
\text { ed by filtration. }\end{array}$ & ntent & & \multirow{2}{*}{$\begin{array}{l}\text { Alkali } \\
\text { content } \\
\text { required } \\
\text { by the } \\
\text { foregoing } \\
\text { formulas }\end{array}$} \\
\hline & Kerp and Bbttger. Sm & mith and Bennett. & crystais. & formulas. & \\
\hline Caesium... & & $4 \cdot 7^{2}$ & $5.05-5.07$ & $\left\{\begin{array}{l}\mathrm{CsHg}_{13} \\
\mathrm{CsHg}_{12}\end{array}\right.$ & $\begin{array}{l}4.86 \\
5.25\end{array}$ \\
\hline Rubidium. & $3.5^{6-3.80}$ & $3 \cdot 55$ & $3 \cdot 48-3 \cdot 53$ & $\left\{\begin{array}{l}\mathrm{RbHg}_{11} \\
\mathrm{RbHg}_{12}\end{array}\right.$ & $\begin{array}{l}3.74 \\
3.44\end{array}$ \\
\hline Potassium. & I. 55 & I. 70 & $1.63-1.64$ & $\left\{\begin{array}{l}\mathrm{KHg}_{11} \\
\mathrm{KHg}_{12}\end{array}\right.$ & $\begin{array}{l}1.75 \\
1.60\end{array}$ \\
\hline Sodium . . & $\begin{cases}\left(0^{\circ}-40^{\circ}\right) & 1.76 \\
\left(42^{\circ}-100^{\circ}\right) & 1.96-2 . \text { I } 5\end{cases}$ & $\begin{array}{l}\ldots \\
\ldots \ldots\end{array}$ & $\begin{array}{l}\text { I. } 2.28-2.28 \\
\text { II. } 2.12-2.13\end{array}$ & $\begin{array}{l}\mathrm{NaHg}_{6} \\
\mathrm{NaHg}_{3}\end{array}$ & $\begin{array}{l}\text { I. } 88 \\
2.25\end{array}$ \\
\hline Lithium ${ }^{1}$. & $\left(0^{\circ}-100^{\circ}\right) 0.70$ & 0.875 & $\begin{array}{l}\text { I. } 1.09-1.09 \\
\text { II. I. 10-I. II }\end{array}$ & $\begin{array}{l}\mathrm{LiHg}_{5} \\
\mathrm{LiHg}_{4} \\
\mathrm{LiHg}_{3}\end{array}$ & $\begin{array}{l}0.70 \\
0.87 \\
\text { I. I } 5\end{array}$ \\
\hline Barium.... & $4.60-4.95$ & $\cdots \cdots$ & $5 \cdot 3^{8-5} \cdot 55$ & $\left\{\begin{array}{l}\mathrm{BaHg}_{13} \\
\mathrm{BaHg}_{12}\end{array}\right.$ & $\begin{array}{l}5.02 \\
5.41\end{array}$ \\
\hline Strontium. & $3 \cdot 33-3 \cdot 42$ & & $3 \cdot 33-3 \cdot 53$ & $\left\{\begin{array}{l}\mathrm{SrHg}_{1 s} \\
\mathrm{SrHg}_{12}\end{array}\right.$ & $\begin{array}{l}3.25 \\
3.52\end{array}$ \\
\hline
\end{tabular}

${ }^{1}$ Kerp and Böttger had very little crystalline lithium amaigam to work with, which necessarily increased the difficulty of separating the mother liquor by filtration on the filter pump. Their low result is evidently due to the presence of mother liquor. 
From the last three columns in the table it is seen that, in spite of the disadvantages of the method, the results tend to indicate the existence of compounds of the formulas $\mathrm{CsHg}_{12}, \mathrm{RbHg}_{12}, \mathrm{KHg}_{12}, \mathrm{NaHg}, \mathrm{LiHg}$, $\mathrm{BaHg}_{12}$ and $\mathrm{SrHg}_{12}$. Nevertheless, the numerical results are misleading, and the only indications which are to be regarded as reliable are those for the sodium and lithium compounds. In the other cases the results prove only that, in the general formula $\mathrm{MeHg}_{n}$, the maximum value of $n$ is 12. It is curious that, in the case of lithium amalgam, Kerp and Böttger, by filtration, obtained values in agreement with the formula $\mathrm{LiHg}_{5}$, while we, by filtration, arrived at the formula $\mathrm{LiHg}_{4}$, and by means of the centrifuge at the formula $\mathrm{LiHg}_{3}$. From his work Maey ${ }^{1}$ deduced the existence of $\mathrm{LiHg}_{5}$, of $\mathrm{LiHg}_{3}$ and of other compounds richer in lithium. His results, however, do not so unmistakably indicate the existence of $\mathrm{LiHg}_{5}$, as they do that of $\mathrm{LiHg}_{3}$.

$\mathrm{Kerp},{ }^{1}$ in his original paper, did not observe the compound $\mathrm{NaHg}_{8}$, and Kerp and Böttger account for this on the assumption that the compound was decomposed during filtration by the pressure that was then exerted upon its surface in order to completely remove the mother liquor. In their common paper ${ }^{1}$ they take exception to the work of Maey, which failed to indicate the existence of a compound richer in mercury than $\mathrm{NaHg}_{5}$. Maey ${ }^{1}$ determined the spacific volumes of amalgams of varying composition, and from the specific-volume curves he deduced the existence of certain definite compounds. Among others, he determined the specific volume of an amalgam containing $I .90$ per cent. of sodium ( $\mathrm{NaHg}_{8}$ requires I $_{2} 88$ per cent.) and obtained the value $0.08 \mathrm{I} 68$. The next amalgam contained 2.63 per cent. of sodium, and for it he obtained the specific volume 0.08545 . We have determined the specific volume of an intermediate amalgam, which contained 2. r2 per cent. of sodium $\left(\mathrm{NaHg}_{5}\right.$ requires 2.25 per cent.) and have obtained the value 0.08277 . It is evident that the compound $\mathrm{NaHg}_{5}$ could not have resulted from a specifically heavier one through the agency of pressure alone. Neither is it at all likely that the solid sticks of amalgam were heated much above the ordinary temperature in the centrifuge. Our results harmonize with those of Maey in denying the existence, at the ordinary temperature, of a compound of the formula $\mathrm{NaHg}_{6}$.

Table II contains the weight of amalgamated metal that is present in Ioo grams of the saturated liquid amalgam. It should be borne in mind however, that these metals are not present in the solution in the free state; they are present in the form of compounds of the general formula $\mathrm{MeHg}_{n}$, dissolved in an excess of mercury. ${ }^{2}$ In the table our own deter-

1 Loc. cit.

2 Cf. Z. anorg. Chem., 58, 381 (1908). 
minations are indicated by asterisks. The other values are those of Kerp and Böttger, which are given for the sake of comparison.

TABLE II.

\begin{tabular}{|c|c|c|c|c|c|c|c|c|}
\hline$t^{\circ}$ & Cs. & Rb. & $\mathrm{K}$. & $\mathrm{Na}$ & Li. & $\mathrm{Ba}$ & sr. & $\mathrm{Ca}{ }^{\mathrm{l}}$ \\
\hline 0 & $* 1.96$ & 0.92 & $0.3 \mathrm{I}$ & 0.54 & 0.04 & 0.15 & 0.73 & $\ldots \ldots$ \\
\hline 18 & $* 2.6 \mathrm{r}$ & $\ldots$ & $\ldots$ & $\ldots$ & $\cdots$ & 0.32 & I. 04 & $\ldots \ldots$ \\
\hline 19.5 & $\ldots$ & $* \mathrm{I} .2 \mathrm{I}$ & $\ldots$ & $\ldots$ & $\cdots$ & $\ldots$ & $\ldots$ & $\ldots \ldots$ \\
\hline 20 & - & $\begin{array}{r}0.47 \\
* 0.46\end{array}$ & . & & $\cdots$ & $\cdots$ & $\cdots$ & \\
\hline 22 & $\cdots$ & $\ldots$ & $\ldots$ & 0.63 & $*_{0.047}$ & $\ldots$ & $\ldots$ & $\ldots \ldots$ \\
\hline 23 & $\ldots$ & $\cdots$ & $\cdots$ & $\cdots$ & $\cdots$ & $\cdots$ & $*_{\text {I. I2 }}$ & $\Rightarrow$ or $>* 0.09$ \\
\hline 24 & $\ldots$ & $\ldots$ & $\ldots$ & $\ldots$ & $\ldots$ & $*_{0} .32$ & $\ldots$ & $\ldots \ldots$ \\
\hline 25 & $\ldots$ & I $\cdot 37$ & 0.53 & 0.65 & $\ldots$ & 0.34 & $\ldots$ & $\cdots \cdots$ \\
\hline 26 & $* 2.98$ & $\ldots$ & $\ldots$ & $\ldots$ & $\cdots$ & $\ldots$ & $\ldots$ & $\ldots \ldots$ \\
\hline 30 & $\ldots$ & $\ldots$ & 0.56 & 0.67 & $\ldots$ & 0.43 & 1.27 & $\ldots \ldots$ \\
\hline $64 \cdot 5$ & $\ldots$ & $\ldots$ & $\ldots$ & $\ldots$ & 0.10 & $\ldots$ & $\ldots$ & $\ldots \ldots$ \\
\hline
\end{tabular}

In conclusion, it is desired to offer an explanation of the well-known fact that, although mercury itself will not adhere to such metals as iron and platinum, even very dilute alkali and alkali-earth amalgams do readily adhere to them. Upon dipping a platinum wire covered with adhering amalgam into dilute hydrochloric acid, the alkali metal is extracted and the resulting mercury does not continue to adhere to the platinum. It has been shown ${ }^{2}$ that, in the decomposition of these amalgams with hydrochloric acid, a point is reached at which there is a sudden increase in the surface tension of the amalgams, accompanied by the sudden evolution of a cloud of minute hydrogen bubbles, and by a sudden decrease in the solution pressure of the amalgams. It wottld appear, therefore, that the adhesion of the amalgams to platinum and to iron is due rather to the inferior cohesion of the amalgams than to any chemical reaction.

URBANA, ILL.

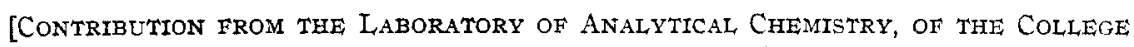
OF THE CITY OF NEW YORK.]

\section{SOME NEW DOUBLE ARSENATES. ${ }^{3}$}

BY Lours J. CurTMan.

Received March II, Igro.

The work on double phosphates ${ }^{4}$ suggested the preparation of corresponding arsenates, especially as reference to the literature showed that

1 We were unable to prepare an amalgam containing more than 0.09 per cent. of calcium. It was filtered at $23^{\circ}$, and was entirely liquid.

2 THIS JOURNAL, 3I, 3 I (I9O9).

${ }^{8}$ Presented in abstract before the Boston Meeting of the American Chemical Society, December, Igog.

4 This JouRNaI, 29, 7 I4 and II94 (I907). 